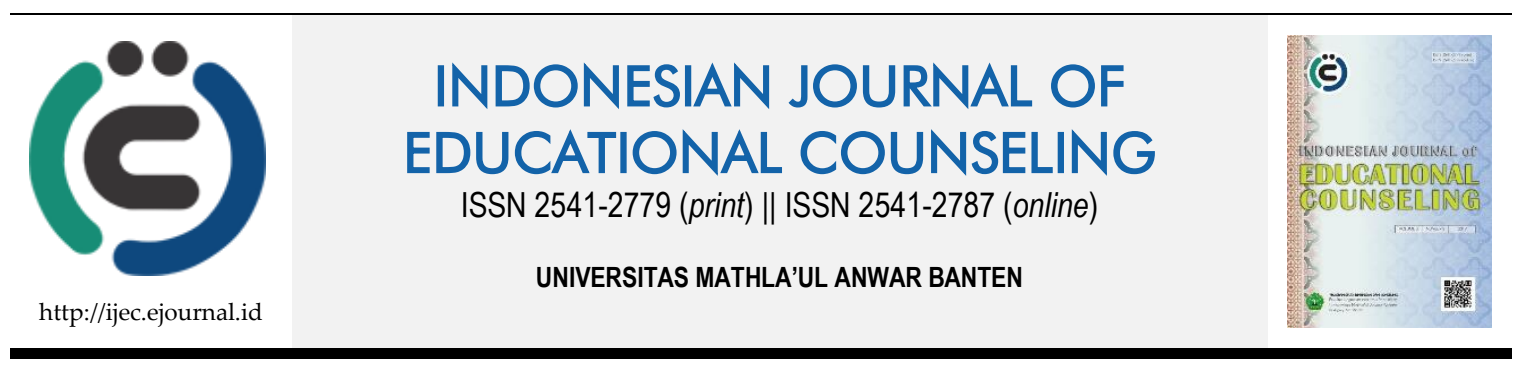

Research Based Article

\title{
Kemanjuran Strategi Mind-Mapping untuk Meningkatkan Keterampilan Berpikir Kreatif dalam Pengambilan Keputusan Karier Siswa
}

\author{
Nur Hidayah'1, M. Ramli², Lutfi Fauzan ${ }^{3}$ \\ 1,2,3 Universitas Negeri Malang
}

\begin{tabular}{ll}
\hline Article History & ABSTRACT \\
\hline Received: 25.03 .2019 & THE EFFECTIVENESS OF MIND-MAPPING STRATEGY TO IMPROVE \\
Received in revised form: & CREATIVE THINKING SKILLS IN STUDENT CAREER DECISION MAKING. \\
01.04 .2019 & The disruptive era in industrial revolution 4.0 is vital for students. In this era, \\
Accepted: 10.04 .2019 & students need creative thinking skills, especially in making career decisions. \\
Available online: 05.08 .2019 & The Mind Mapping strategy is the right choice to train students' creative \\
& thinking skills. This creative thinking skills training is intended for students of \\
& Malang State High School Laboratory, class XII MIPA, IPS, IBB, and ICP. The \\
& expected goal is to increase the creative thinking skills of Malang State \\
& University High School Laboratory students in their career decision making. \\
& Based on the results of the study showed that creative thinking skills in career \\
& decision making before and after being trained with mind-mapping strategies, \\
there was a significant increase. The Wilcoxon test results were Z $=4,644$ with a \\
significance of $0,000$. That is, there are significant differences in creative \\
thinking skills in student career decision making before and after being trained \\
with mind-mapping strategies.
\end{tabular}

KEYWORDS: Career Decision Making, Creative Thinking Skills, Industrial Revolution 4.0 Era, Mind Mapping Strategy.

DOI: $10.30653 / 001.201933 .109$

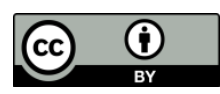

This is an open access article distributed under the terms of the Creative Commons Attribution 4.0 International License, which permits unrestricted use, distribution, and reproduction in any medium, provided the original work is properly cited. @ 2019 Nur Hidayah, M. Ramli, Lutfi Fauzan.

\section{PENDAHULUAN}

Generasi milineal dikenal dengan generasi now, telah memasuki era disrupsi pada revolusi industri 4.0. Era disrupsi ditandai dengan segala urusan dalam kehidupan manusia telah menjadi lebih mudah, baik dari sisi akses, efisiensi waktu, dan keakuratan tujuan (Leksono, 2018). Era disrupsi adalah masa ketika perubahan terjadi sedemikian tidak terduga, mendasar dan hampir dalam semua aspek kehidupan. Tatatan baru hadir menggantikan tatanan lama yang sudah tidak sesuai dengan perkembangan zaman 
(Bashori, 2018). Adanya inovasi-inovasi baru tersebut tidak jarang menimbulkan dampak yang pro atau kontra terhadap tatanan-tatanan yang sebelumnya.

Dunia pendidikan juga termasuk bagian kehidupan yang terdampak era disrupsi ini. Salah satu fenomena tersebut muncul pada adanya perkembengan teknologi dan perkembangan akses informasi menjadikan layanan buku digital lebih diminati siswa ketimbang buku-buku cetak. Kondisi ini selanjutnya turut berdampak pada tugas-tugas yang diberikan guru, kemahiran penggunaan internet menjadi faktor pendukung terselesaikannya tugas siswa.

Kondisi tersebut menjadikan siswa perlu untuk lebih kompetitif dalam menghadapi kehidupan di sekolah, generasi yang tidak bisa lepas dengan internet-gedget. Siswa SMA merupakan generasi yang senantiasa menghadapi tantangan global. Siswa yang mampu bersaing di era disrupsi ini tidak hanya dilatih untuk mengembangkan sikap dasar dan kemahiran penggunaan teknologi, akan tetapi harus disiapkan untuk mengasah kemampuan berpikir untuk menunjang daya saingnya. Oleh karena itu, upaya peningkatan mutu pendidikan mempunyai makna menyiapkan siswa untuk menjadi generasi masa depan yang berkualitas.

Salah satu kemampuan berpikir yang sering diabaikan oleh pihak sekolah SMA Laboratorium Universitas Negeri Malang adalah kemampuan berpikir kreatif. Sekolah lebih memberikan perhatian pada hasil belajar akademik. Siswa dikatakan berhasil, bila mendapatkan nilai akademik yang tinggi. Kemampuan mental yang dilatihkan oleh Guru BK di SMA Laboratorium Universitas Negeri Malang adalah kemampuan untuk menemukan satu jawaban yang dianggap benar dan tepat. Siswa tidak terbiasa untuk berpikir kreatif, sehingga kemampuan tersebut tidak tercermin dan muncul dalam kehidupan sehari-hari.

Sampai saat ini, pelatihan khusus yang ditujukan untuk meningkatkan kreativitas siswa masih sangat kurang (Antonietti \& Cesa-Bianchi, 2003; Pizzingrillia et al., 2015). Meskipun para guru memiliki pengetahuan yang memadai tentang konsep kreativitas, belum ada bahkan masih kurangnya instrumen untuk mengevaluasi kreativitas siswa. Beberapa peneliti (Antonietti, Colombo, \& Pizzingrilli, 2011; Giorgetti, Pizzingrilli, \& Antonietti, 2009; Kampylis, P. \& Berki, 2014; Pitts, Anderson, \& Haney, 2018) mencoba mengintegrasikan perspektif klasik utama mengenai kreativitas, serta kontribusi yang lebih baru. Model yang dihasilkan mengasumsikan bahwa proses kreatif terdiri dari tiga mekanisme mental, sesuai dengan tiga prinsip utama yang mendasari teori klasik: (1) kemampuan untuk memiliki pikiran yang terbuka, menghasilkan sejumlah besar ide yang berbeda (Widening); (2) kemampuan untuk membuat kombinasi yang tidak biasa antara gagasan yang berbeda dan dikenal (Connecting); dan (3) kemampuan untuk menangkap dan merestrukturisasi sifat-sifat baru dari suatu situasi tertentu dengan ide untuk mengambil perspektif yang berbeda (Reorganizing). Ketiga aspek tersebut merupakan salah satu paparan bagaimana wujud dari kreatifitas yang dibutuhkan oleh individu, secara khusus para siswa dalam mengambil keputusan karier.

Keterampilan berpikir kreatif merupakan kemampuan mencipta hal-hal baru di bidang ilmu yang dikuasai (Gardner, 1993, 2007). Berpikir kreatif merupakan keterampilan berpikir terkait dengan hal-hal baru, kemampuan untuk membuat sesuatu, menerapkan bentuk-bentuk baru, untuk menghasilkan banyak keterampilan imajinatif 
atau untuk membuat sesuatu yang sudah ada menjadi sesuatu yang baru (Greenstein, 2012). Keterampilan ini merupakan keterampilan yang sangat dibutuhkan untk menghadapi era disrupsi pada abad 21 ini.

Abad 21 merupakan suatu periode kehidupan yang ditandai oleh era globalisasi, informasi, Masyarakat Ekonomi Asia (MEA), dan AFTA (Hidayah, 2015). Gardner (2007) mendefinisikan berpikir kreatif sebagai kesanggupan untuk memperjelas problem, pertanyaan, dan fenomena-fenomena baru. Berpikir kreatif membantu siswa memproduksi cara-cara dan mendefinisikan pertanyaan baru tentang masalah yang ditemui (Gardner, 1993). Sternberg (2012) menyebutkan kreativitas memerlukan pertemuan dari enam sumber yang berbeda dan saling berhubungan, yakni kemampuan inteligensi, pengetahuan, gaya berpikir, kepribadian, motivasi, dan lingkungan. Kreativitas terdiri atas tiga keterampilan, yaitu analitik, sintetik, dan praktikal. Keterampilan berpikir kreatif merupakan keterampilan berpikir tingkat tinggi.

Keterampilan berpikir kreatif merupakan interaksi antara diri siswa dengan lingkungan. Siswa dipengaruhi dan mempengaruhi lingkungan. Perubahan yang terjadi dalam diri siswa maupun perubahan dalam lingkungan dapat mendukung atau menghambat keterampilan berpikir kreatif siswa. Keterampilan berpikir kreatif siswa dapat ditingkatkan melalui layanan bimbingan pribadi. Pelatihan keterampilan berpikir kreatif dapat dilakukan dengan sejumlah strategi di antaranya adalah model analogi, Socratic dialogue, problem solving, dan mind mapping (Hidayah, 2015). Salah satu kondisi yang dapat mendukung diadakannya pelatihan untuk mengembangkan keterampilan berpikir kreatif adalah psikoedukasi dalam bimbingan kelompok dengan menggunakan strategi mind mapping. "Mind mapping" adalah gambar atau peta pemikiran yang terorganisir secara visual dari ide dan konsep yang digunakan untuk memfasilitasi ide dasar yang ada dalam pikiran. Ide dan konsep ditata menyerupai cara otak bekerja, yaitu link atau asosiasi. Mind mapping dilakukan dengan menghubungkan satu ide dengan ide lainnya dengan bantuan warna dan gambar untuk memanfaatkan kedua sisi otak. Ketika proses itu terjadi, kreativitas mendapat dorongan tanpa mengorbankan rasa-logika (Buzan, 1993, 2011; Davies, 2011).

Hasil penelitian Lee (2004) menunjukkan bahwa pembelajaran pada beberapa sistem pendidikan dipandang kurang dalam pengembangan pengajaran berbasis kreatif. Pendidik cenderung menghambat kreativitas dengan mengajak siswa untuk menghafal teori (Ranjan, A. \& Gabora, 2012). Guru takut untuk mengembangkan keterampilan berpikir kreatif siswa di dalam kelas karena kelas menjadi kacau dan tidak sesuai dengan skenario pembelajaran (Ranjan, A. \& Gabora, 2012). Demikian temuan Rosalina (2015) menunjukkan bahwa strategi mind mapping dapat meningkatkan keterampilan pengambilan keputusan karier siswa SMA.

Keterampilan berpikir kreatif siswa dalam pengambilan keputusan karier belum terasah, dimungkinkan karena belum adanya usaha dari pihak sekolah untuk memberikan stimulasi kepada siswa untuk mengembangkan keterampilan berpikir kreatif. Siswa hanya berhenti dari apa yang diperoleh dari guru, tanpa ada usaha dari siswa untuk mengolah informasi yang diperoleh. Penggunaan internet pun turut menghasilkan hasil yang sama, kurang adanya campur tangan para guru untuk membimbing siswa menghasilkan hasil pembelajaran yang lebih kreatif. 
Berdasar pada hasil wawancara dengan guru BK/konselor SMA Laboratorium Universitas Negeri Malang ditunjukkan bahwa para siswa belum memiliki keterampilan berpikir berorientasi dari sudut pandang yang berbeda ketika menghadapi problem - ciri khas berpikir kreatif, bahkan cenderung berpikir statis dan prosedural. Berdasarkan need asesmen menunjukkan bahwa problem terbanyak siswa kls XII adalah bidang karier. Para guru BK/konselor berharap agar siswa memiliki keterampilan berpikir kreatif dalam menghadapi tantangan zaman now. Pada gilirannya siap menghadapi tantangan arus globalisasi. Para siswa diharapkan memiliki tanggungjawab sebagai pelajar dan terampil memecahkan persoalan-persoalan di masa yang akan datang, termasuk dalam pengambilan keputusan kariernya. Tujuan penelitian ini adalah meningkatkan keterampilan berpikir kreatif siswa dalam pengambilan keputusan karier dengan strategi mind mapping.

\section{METODE}

\section{Rancangan Penelitian}

Penelitian ini dilakukan menggunakan metode penelitian eksperimen melalui rancangan one group pretest-posttest design yang dikemukakan Isaac dan Michael (1981). One group pretest-posttest design dipilih karena desain ini sesuai untuk mengubah pola perilaku maupun proses internal (kognitif) yang cenderung stabil dan memerlukan usaha yang signifikan untuk mengubahnya (Creswell, 2013; Gall, Gall, \& Borg, 2003). Kondisi keterampilan berpikir keratif siswa SMA Laboratorium yang merupakan pola perilaku kognitif yang cenderung stabil merupakan sasaran yang sesuai untuk desain penelitian ini.

Perbedaan (selisih) antara posttest (T2) terhadap pretest (T1) merupakan pengaruh atas adanya intervensi atau treatment. Analisa atas perbandingan skor pretest dan posttest akan menunjukkan tingkat keberhasilan intervensi atau treatment. Intervensi menunjukkan tingkat keberhasilan tinggi apabila skor posttest (T2) memiliki perbedaan yang signifikan terhadap skor pretest (T1). Rancangan pengujian eksperiman tersebut tersaji dalam Tabel 1.

Tabel 1. Desain Rancangan Pengujian Keefektifan Produk

\begin{tabular}{lll}
\hline Prestest & Treatment & Posttest \\
\hline T1 & $\mathrm{X}$ & T2
\end{tabular}

Keterangan:

$\mathrm{T}_{1} \quad$ : Pretest. Pengukuran kondisi pencapaian meaning of life budaya Osing Siswa SMP sebelum diberikan treatment.

X : Treatment berupa pelaksanaan teknik Coping skills bermuatan nilai budaya Osing untuk pemenuhan meaning of life siswa.

$\mathrm{T}_{2}$ : Posttestt. Pengukuran kondisi pencapaian meaning of life budaya Osing Siswa SMP sesudah diberikan treatment. 


\section{Prosedur Penelitian}

\section{Tahap Persiapan}

Pada tahap ini peneliti melaksanakan penjaringan siswa untuk menjadi peserta pelatihan. Peserta pelatihan merupakan 40 siswa kelas XII SMA Laboratorium UM yang dipilih secara acak. Seluruh 40 siswa tersebut selanjutnya melakukan pengisian inventori keterampilan berpikir kreatif sebagai bentuk pretest.

\section{Tahap Pelaksanaan dan Implementasi Treatment}

Tahap ini merupakan tahap inti berupa pelaksanaan treatment pelatihan strategi mind mapping untuk meningkatkan keterampilan berpikir kreatif siswa. Pelaksanaan pelatihan dilaksanakan pada waktu yang berbeda setelah dilakukan pretest.

Pada tahap ini siswa dikumpulkan untuk mengikuti pelatihan menggunakan strategi mindmapping untuk meningkatkan keterampilan berpikir kreatif siswa SMA Laboratorium UM. Pelatihan dilaksanakan selama 2 hari dengan materi berupa "Orientasi Keterampilan Berpikir Kreatif"; "Keterampilan Berpikir Kreatif dalam Era Revolusi Industri 4.0"; "Pengembangan Keterampilan Berpikir Kreatif menggunakan Strategi Mindmapping"; "Berlatih Keterampilan Berpikir Kreatif menggunakan Strategi Mindmapping". Pada akhir tahap ini dilakukan refleksi atas seluruh materi yang telah didapatkan siswa

\section{Tahap Pengakhiran}

Pada tahap ini dilakukan pengujian posttest siswa pada waktu yang berbeda. Pengujian posttest masih menggunakan instrumen yang sama, yakni inventori berpikir kreatif siswa.

\section{Teknik Pengumpulan Data}

Pengumpulan data dilakukan melalui instrumen berupa inventori keterampilan berpikir kreatif siswa SMA Laboratorium UM. Inventori tersebut telah dikembangkan peneliti dengan memenuhi unsur realibilitas dan validitas. Inventori keterampilan berpikir kreatif siswa SMA tersebut memiliki 50 item dengan 4 piliha jawaban "Sangat Sesuai"; "Sesuai"; "Kurang Sesuai" dan "Tidak Sesuai".

\section{Teknik Analisis Data}

Teknik analisis terhadap data pretest dan posttest yang telah didapatkan menggunakan teknik analisis statistik melalui pengujian wilcoxon dan paired samples ttest.Pengujian wilcoxon dilakukan untuk mengetahui perbedaan pada hasil pretest dan posttest siswa. Sedangkan pengujian paired samples t-test dilakukan untuk melihat signifikansi dari perbedaan pretest dan posttest. Proses analisis dilakukan menggunakan bantuan media software IBM SPSS Statistik ver.21. 


\section{HASIL DAN PEMBAHASAN}

Peserta pelatihan keterampilan berpikir kreatif sebanyak 40 orang siswa. Secara umum mereka memperoleh peningkatan keterampilan berpikir kreatif dalam pengambilan keputusan karier. Peningkatan tersebut ditunjukkan dari hasil perbandingan skor pretest dan posttest keterampilan berpikir kreatif yang cukup signifikan dari aspek pemahaman dan kinerja/praktik. Aspek pemahaman diukur dari skala berpikir kreatif, sedangkan aspek keterampilan diukur dari kinerja pada saat praktik/simulasi.

Tabel 2. Hasil Uji Wilcoxon

\begin{tabular}{lllll}
\hline & & N & Mean Rank & Sum of Ranks \\
\hline \multirow{3}{*}{ Posttest - Pretest } & Negative Ranks & 5a & 9.80 & 49.00 \\
\cline { 2 - 5 } & Positive Ranks & 33b & 20.97 & 692.00 \\
\cline { 2 - 5 } & Ties & 2c & & \\
\cline { 2 - 5 } & Total & 40 & & \\
\hline
\end{tabular}

a. Posttest $<$ Pretest

b. Posttest $>$ Pretest

Posttest $=$ Pretest

Tabel 3. Tabel Statistik

\begin{tabular}{ll}
\hline & Posttest - Pretest \\
\hline$Z$ & $-4.664 \mathrm{~b}$ \\
\hline Asymp. Sig. (2-tailed) & .000 \\
\hline
\end{tabular}

a. Wilcoxon Signed Ranks Test

b. Based on negative ranks.

Pada Tabel 2 menjelaskan pola hubungan perbedaan dari keseluruhan siswa hasil pretest dan posttest. Terbaca di tabel bahwa sebanyak 33 orang siswa memiliki perbedaan positif-ada peningkatan skor, sebanyak 5 orang siswa memiliki perbedaan negatif-ada penurunan skor, dan sebanyak 2 siswa tidak memiliki perbedaan antara hasil pretest dan posttest.

Pada Tabel 3 didapatkan hasil Asymp. Sig. (2-tailed) pada koefisien 0,000. Angka tersebut dapat dimaknai bahwa terdapat perbedaan peningkatan antara hasil pretest dan posttest.

Tabel 4. Hasil Uji T berpasangan (Paired-t Test)

Paired Samples Test

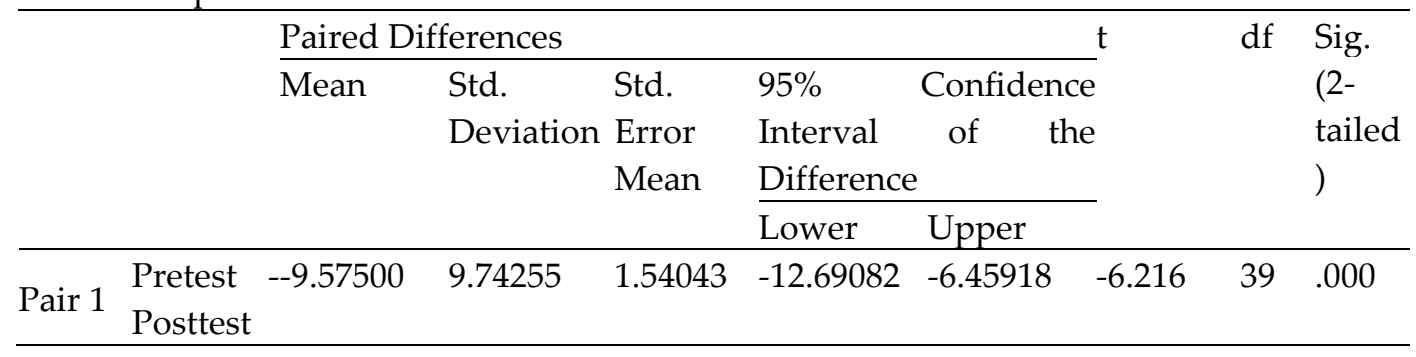


Tabel 4 menunjukkan angka signifikansi pada kolom Sig. (2-tailed) sebesar 0.000, sehingga dapat dimaknai bahwa perbedaan peningkatan hasil pascates terhadap prates adalah perbedaan peningkatan yang signifikan.

Peningkatan keterampilan berpikir kreatif siswa merupakan hasil yang diharapkan dalam penelitian ini. Hasil tersebut menunjukkan bukti keefektifan strategi mind mapping untuk meningkatkan keterampilan berpikir kreatif siswa SMA Laboratorium UM. Pelaksanaan treatment ini sejalan dengan hasil penelitian zubaidah dkk. (2017) yang menyatakan bahwa keterampilan berpikir kreatif siswa merupakan hasil latihan. Selanjutnya, selain dilakukannya treatment yang berupa pelatihan, konselor sekolah perlu untuk terus memantau kelanjutan latihan dari para siswa.

Di sisi lain, penggunaan strategi mindmapping memiliki kelebihan berupa representasi visual sangat membantu untuk menghasilkan ide-ide serta mengatur dan merangkum pemikiran siswa secara grafis (Joao \& Silva, 2014). Representasi visual tersebut menjadi paparan gagasan dan informasi yang didapatkan siswa. Paparan gagasan tersebut menjadikan struktur pikiran menjadi terbuka dan terorganisir, memungkinkan seseorang untuk mengatur berbagai informasi dan membangkitkan lebih banyak ide baru (Wang, Lee, \& Chu, 2010).

Kelebihan strategi mind mapping yang lain adalah strategi ini memanfaatkan semua keterampilan yang umumnya dikaitkan dengan aspek kognitif, terutama imajinasi, menghubungkan gagasan, dan fleksibilitas. Penggunaan mind map juga akan memudahkan siswa dalam mengelola dan memahami informasi secara efektif dan sistematis (Zubaidah et al., 2017). Kemampuan untuk mengelola dan memahami informasi adalah kunci untuk mencapai lima aspek pemikiran kreatif. Berdasarkan asumsi-asumsi ini, penggunaan mind-mapping diharapkan dapat memetakan pikiran siswa dan memprovokasi pemikiran mereka ke segala arah dan pada akhirnya membawa ide-ide brilian dan kreatif (Buzan, 2011).

Bukti keefektifan treatment berupa pelatihan strategi mind-mapping ini pada akhirnya dapat menjadi alternatif layanan untuk meningkatkan keterampilan berpikir siswa SMA. Hal ini dikarenakan konselor yang mengampu generasi milenial perlu untuk memiliki karakter CINTA (Congruence, Inovatif, Normative, Trusted, and Awareness). Melalui karakter tersebut, konselor dapat membimbing siswa untuk memiliki karakter kreatif, konentif dan konfiden.

Pada akhirnya, para siswa dapat melakukan life long learning untuk dapat bertahan pada era disrupsi di masa revolusi industri 4.0 melalui keterampilan berpikir kreatifnya. Keterampilan berpikir kreatif yang tinggi, diharapkan dapat membantu siswa dalam menguasai perkembangan teknologi melalui inovasi-inovasinya. Meski demikian, keterampilan-keterampilan berpikir yang lain turut perlu diperhatikan bagi para generasi milenial atau generasi zaman now.

Konselor yang membimbing siswa zaman now turut memiliki tanggung jawab dalam menyiapkan penguatan karakter siswa. Karakter-karakter tersebut antara lain religiusitas, integritas, nasionalis mandiri, dan gotong royong. Selain itu, konselor turut perlu untuk menumbuhkan keterampilan literasi siswa yang terdiri atas baca, tulis, sain, 
dan keuangan. Terakhir, konselor juga memiliki peran untuk meningkatkan $4 \mathrm{C}^{\prime} \mathrm{S}$ siswa, yakni critical thinking skill, creative thinking skill, collaboration skill, dan communication skill.

\section{SIMPULAN}

Pelatihan peningkatan keterampilan berpikir kreatif dalam pengambilan keputusan karier siswa SMA Laboratorium Universitas Negeri Malang ini diketahui meningkat dari aspek pemahaman dan kinerja/keterampilan. Dilihat dari selisih antara skor posttest dan prates ada peningkatan secara signifikan. Beberapa saran yang diberikan adalah berikut: (1) Guru BK dapat melatihkan keterampilan berpikir kreatif kepada semua siswa SMA Laboratorium Universitas Negeri Malang melalui program peer helper, (2) dilakukan pendampingan oleh guru BK, agar keterampilan berpikir kreatif siswa terasah secara terus menerus, (3) perlu dirancang pelatihan keterampilan berpikir kritis siswa, agar kedua keterampilan berpikir tersebut berkembang seimbang.

\section{REFERENSI}

Antonietti, A., \& Cesa-Bianchi, M. (2003). Creatività nella vita e nella scuola. Milano: Mondadori.

Antonietti, A., Colombo, B., \& Pizzingrilli, P. (2011). The WCR model of creativity: From concept to application. The Open Education Journal, 4, 80-89.

Bashori, K. (2018). Pendidikan politik di era disrupsi. Sukma: Jurnal Pendidikan, 2(2), 287310.

Buzan, T. (1993). The mind map book. London: BBC Book.

Buzan, T. (2011). Mind Maps ${ }^{\circledR}$ : A Powerful Approach to Note-Taking [Internet]. Retrieved May 14, 2018, from http://www.mindtools.com/pages/article/newISS_01.htm

Creswell, J. W. (2013). Educational research: Planning, conducting, and evaluating. Brantford, ON: W. Ross MacDonald School Resource Services Library.

Davies, M. (2011). Concept mapping, mind mapping and argument mapping: What are the differences and do they matter?. Higher Education, 62(3), 279-301.

Gall, M. D., Gall, J. P., \& Borg, W. R. (2003). Educational research an introduction, Seventh editions. Oregon: University of Oregon.

Gardner, H. (1993). Creating Minds. An Anatomy of creativity seen through the lives of Freud, Einstein, Picasso, Stravinsky, Eliot, Graham, and Gandhi. New York: Basic Books.

Gardner, H. (2007). Five minds for the future (Lima jenis pikiran yang penting di masa depan). Jakarta: Gramedia Pustaka Utama. 
Giorgetti, M., Pizzingrilli, P., \& Antonietti, A. (2009). Creative problem solving. A new instrument to assess children's idea generation, unusual association and cognitive restructuring. In Proceeding of the Conference Excellence in Education "Leading MindsCreating the Future". Ulm, 24-27 August 2009.

Greenstein, L. M. (2012). Assessing 21st century skills: A guide to evaluating mastery and authentic learning. Thousand Oaks, California: Corwin Press.

Hidayah, N. (2015). Mengasah keterampilan berpikir kritis dan kreatif. prosiding seminar nasional bimbingan dan konseling: revolusi mental dalam bimbingan dan konseling. Surabaya: ABKIN dan Universitas PGRI Adi Buana Surabaya.

Isaac, S., \& Michael, W. B. (1981). Handbook in research and evaluation. California: Edits Publishers.

Joao, I. M., \& Silva, J. M. (2014). Concept mapping and mind mapping to lift the thinking skills of chemical engineering students. International Journal of Engineering Pedagogy (IJEP), 4(5), 42-48.

Kampylis, P. \& Berki, E. (2014). Nurturing creative thingking [Internet]. Retrieved May 20, 2018, from International Academic Education website: http://unesdoc.unesco.org/images-/0022/-002276/227680epdf

Lee, Y. J. (2004). Effects of divergent thinking training/instructions on torrance of creative thinking and creative performance. Tennesse: University of Tennesse.

Leksono, N. (2018). Pembangunan, pluralitas, dan era disrupsi. In Seminar Dies Natalis XXV Fakultas Sastra, Multikulturalisme dalam Perspektif Pendidikan Humaniora di Era Disrupsi. Yogyakarta: Universitas Sanata Dharma.

Pitts, C., Anderson, R., \& Haney, M. (2018). Measures of instruction for creative engagement: Making metacognition, modeling and creative thinking visible. Learning Environments Research, 21(1), 43-59.

Pizzingrilli, P., Valenti, C., Cerioli, L., \& Antonietti, A. (2015). Creative thinking skills from 6 to 17 years as assessed through the WCR test. Procedia-Social and Behavioral Sciences, 191, 584-590.

Ranjan, A. \& Gabora, L. (2012). Creative Ideas for Actualizing Student Potential. In H. Sneyder, M. Gregerson, \& J. Kaufman (Eds.), Teaching creatively (pp. 119-132). Berlin: Springer.

Rosalina, I. (2015). Kemanjuran penerapan synectic model dan mind mapping untuk meningkatkan kreativitas pengambilan keputusan karier siswa SMA. Malang: Universitas Negeri Malang. 
Sternberg, R. J. (2012). Assessment of Creativity: An Investmen-Based Approach. Creativity Research Journal, 24(1), 3-12.

Wang, W. C., Lee, C. C., \& Chu, Y. C. (2010). A brief review on developing creative thinking in young children by mind mapping. International Business Research, 3(3), 233-238.

Zubaidah, S., Fuad, N. M., Mahanal, S., \& Suarsini, E. (2017). Improving creative thinking skills of students through Differentiated Science Inquiry integrated with mind map. Journal of Turkish Science Education, 14(4), 77-91. 